\title{
Diagnostics of Automobile Mechatron Systems by Integrated Environmental Indicators
}

\author{
I. F. Suleimanov ${ }^{1}$, D. A. Kharlyamov*2, G. V. Mavrin ${ }^{3}$, A. A. Goncharov ${ }^{4}$, P. A. Goncharov ${ }^{5}$, A. N. Melnikov ${ }^{6}$ \\ ${ }^{1}$ Kazan Federal University, Naberezhnye Chelny Institute, ${ }^{2,3}$ Kazan Federal University, Naberezhnye Chelny Institute, \\ 4, 5, 6 Orenburg State University \\ Email: kharlyamov@gmail.ru
}

\section{Received: 21st October 2017 Accepted: 16th November 2017, Published: 31st December 2017}

\begin{abstract}
The current level of motorization makes high demands on the reliability of vehicles, to the provision of technical and economic properties and to reduce the technogenic impact, primarily - the emissions of harmful substances into the environment. The world automobile industry is currently developing in the direction of electronic engine management system use to improve the quality of vehicle operation, fuel efficiency and environmental safety.

The analysis of automotive internal combustion engine performance equipped with electronic control systems showed that at the first stages the design improvement led to functional and parametric failure increase, as well as to their qualitative change. In this regard, the need appeared to develop new methods and tools for diagnosis. Thus, the problem of new methods creation and the development of existing methods to diagnose electronic engine control systems is topical.

The research was carried out using the elements of system analysis and decision theory, mathematical modeling, probability theory and mathematical statistics, the theory of expert evaluations, image recognition and experimental research.

The paper demonstrated the results of the mathematical model development for the interrelation of the technical state of element parameters concerning automotive mechatronic systems with the output parameters of automobile engines, diagnostic algorithms, and the experimentally obtained parameters of diagnostic areas.

The obtained results are diagnostic algorithms, diagnostic parameter values and their interpretation which allow to reduce the time spent on the troubleshooting of automotive mechatronic systems during car maintenance and repair.

The developed theoretical positions, the results of experimental research and practical recommendations are intended for the use in motor transport and service enterprises during the servicing and the repair of mechatronic automotive systems.
\end{abstract}

Keywords: Mechatronic Systems, Cars, Diagnostics, Electronic Engine Management Systems, Telematics

\section{Introduction}

The purpose of the performed study is to increase the efficiency of vehicle mechatronic system operation on the basis of diagnostic methodology improvement according to a comprehensive environmental indicator, which consists in the obtaining of diagnostic information in real time using telematics.

It is known that telematics tools are widely used to monitor the rolling stock on a route and to ensure its transport security [1-6]. At the same time, there is a wide range of practical tasks to be solved using the same tools related to the rapid assessment of the technical condition of vehicles and the transfer of this information to the responsible technical services.

During the research, the technique for the diagnosing automobile engine mechatronic systems was developed, characterized by the use of normalized environmental indicator remote monitoring interconnected with the parameters of an electronic engine management system technical state.

They studied the relationship between the concentration of exhaust gas components $\left(\mathrm{CO}\right.$ and $\left.\mathrm{O}_{2}\right)$ in front of the catalytic converter of exhaust gases with the faults of electronic system elements for an engine control. At the theoretical stage of the study the mathematical model was developed that includes the expressions describing the relationship between environmental diagnostic parameters and the technical condition parameters of mechatronic system elements, as well as the system of limitations for characteristic diagnostic areas based on the provisions of an image recognition theory.

The result of the studies is the establishment of model parameters and the characteristics of diagnostic areas using the example of electronic control systems for LADA vehicles, they determined the possibilities of telematics complex use installed on new vehicles for operational monitoring of mechatronic system state and environmental indicators.

\section{Methods}

The assessment of the $\mathrm{P}_{\text {ecol }}$ environmental indicator should be made on the basis of the components contained in the exhaust gases of an engine. The most significant components of the engine exhaust gases by concentration and toxicity are $\mathrm{CO}, \mathrm{CO}_{2}, \mathrm{CH}, \mathrm{O}_{2}$ and NOx. According to GOST 17.2.2.03-87 and 517092001 it is necessary to define two ecological indicators $\mathrm{CO}$ and $\mathrm{CH}$. Based on the design of the device in order 
to determine the concentration of various components of the exhaust gases of an engine, we can draw the following conclusion:

- indicators $\mathrm{CO}, \mathrm{CH}$ and $\mathrm{CO}_{2}$ are determined by the method of infrared spectroscopy;

- $\mathrm{O}_{2}$ and NOx values are determined by the electrochemical method.

Therefore, it is necessary and sufficient to select one component from each group for a comprehensive assessment of the environmental indicator.

Taking into account the earlier studies and the correlation links between components from each group, only one component can be regarded - $\mathrm{CO}$ and $\mathrm{O}_{2}$.

The determination of $\mathrm{CO}$ concentration by calculation using the standard program "Motor-tester" makes it possible to find the parameter in different modes. Also using this program, it is possible to obtain information on the amount of air in $\mathrm{kg} / \mathrm{h}$ entering the engine and thus to determine the excess air coefficient by the following formula:

$$
\alpha=\frac{G_{B}}{14,7 G_{T}},(1)
$$

where GB is the air flow rate, $\mathrm{kg} / \mathrm{h} ; \mathrm{GT}$ - fuel consumption, $\mathrm{kg} / \mathrm{h}$.

The CO concentration value is used to determine the weight content of the i-th component and is expressed by the following equation:

$$
G_{i}=C_{i} \cdot \frac{\gamma_{i}}{\gamma_{s}} \cdot\left(G_{B}+G_{T}\right)
$$

where $G_{B}$ is the air flow rate, $\mathrm{kg} / \mathrm{h} ; \mathrm{G}_{\mathrm{T}}$ - fuel consumption, $\mathrm{kg} / \mathrm{h} ; \mathrm{C}_{\mathrm{i}}$ - concentration of the i-th component in the exhaust gases, $\%$ by volume; $\gamma_{\mathrm{i}}$ is the density of the $\mathrm{i}$-th component, $\mathrm{kg} / \mathrm{m}^{3} ; \gamma_{\mathrm{s}}$ is the density of the exhaust gases, $\mathrm{kg} / \mathrm{m}^{3}$.

On the other hand, in order to determine the weight content of the i-th component, it is possible to use a private method to calculate carbon monoxide emissions of a car with a gasoline engine, proposed by L.S. Sukhareva:

$$
G_{C O}=4,17 G_{T}(1-\alpha),(3)
$$

where $\mathrm{G}_{\mathrm{T}}$ - the fuel flow rate, $\mathrm{kg} / \mathrm{h}$.
Equating the right-hand sides of equations (2) and (3), we obtain the following:

$$
C_{C O} \cdot \frac{\gamma_{C O}}{\gamma_{s}} \cdot\left(G_{B}+G_{T}\right)=4,17 G_{T}(1-\alpha),
$$

where the concentration of $\mathrm{CO}$ in different modes is determined by the following formula:

$$
C_{C O}=\frac{4,17(1-\alpha) \gamma_{S}}{\gamma_{C O}(14,7 \alpha+1)},(5)
$$

The determination of $\mathrm{O}_{2}$ concentration by calculation using the standard program "Motor tester" is carried out similarly, but taking into account the density of this component.

$$
C_{O 2}=\frac{4,17(1-\alpha) \gamma_{S}}{\gamma_{O 2}(14,7 \alpha+1)},(6)
$$

The developed methodology for complex indicator estimation obtained by stand free method using "Motor Tester" program allowed to monitor the technical condition of cars with EECS and it is an alternative to gas analyzers [7-8].

Previous studies have shown that the change of the working mixture composition leads to the change in the composition of exhaust gases, the main components of which are $\mathrm{CO}$ and $\mathrm{O}_{2}$. The results of theoretical and experimental studies indicate a significant effect of the technical state concerning the elements of mechatronic systems on the parameters of $\mathrm{CO}$ and $\mathrm{O}_{2}$.

The conventional methods of experiment planning, the processing of experiment results, and developed private methods were used in the course of research:

- the establishing of $\mathrm{CO}$ and $\mathrm{O}_{2}$ concentration dependencies on the program value of the fuel system static performance $q_{c m}^{n}$;

- the modeling of characteristic faults in the elements of mechatronic motor systems;

- the establishment of reference diagnostic areas.

In order to analyze the functioning of an automobile engine with an electronic control system, the structural diagram was designed and shown on Fig. 1. 


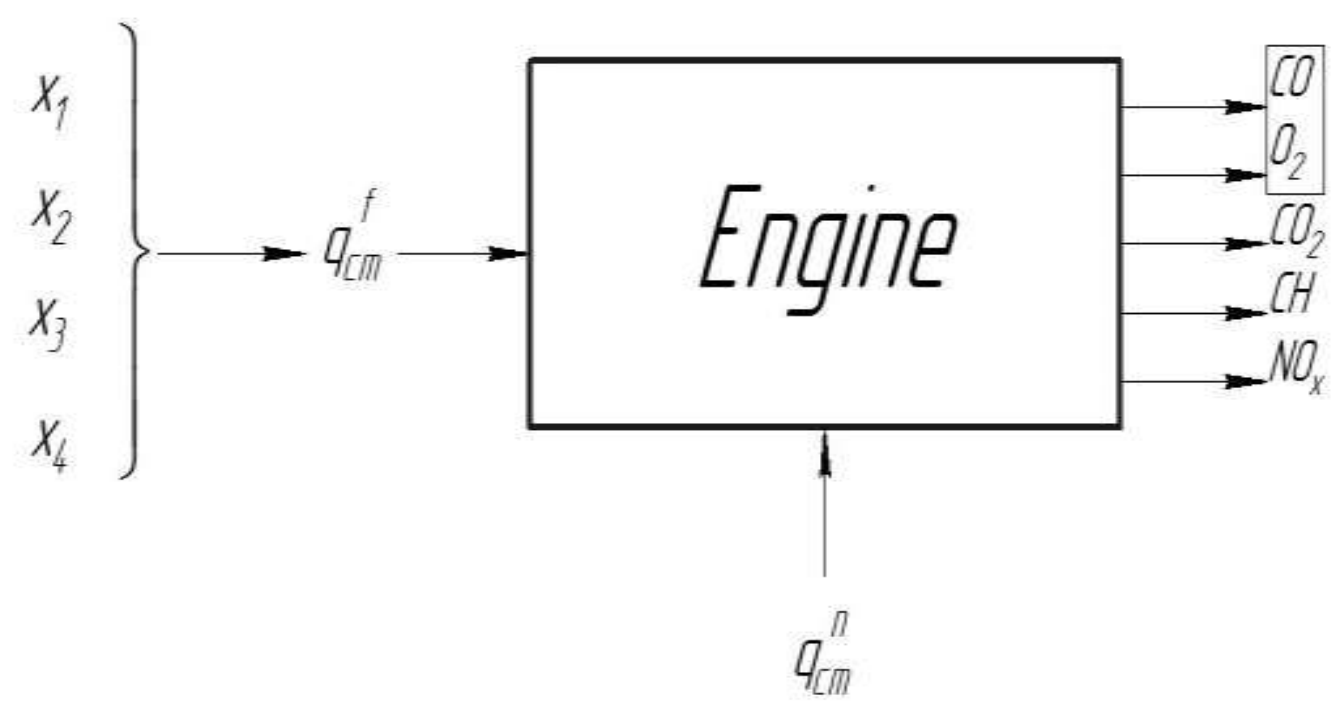

Fig. 1. Structural Diagram of an Automobile Engine with an Electronic Control System $\left(\mathrm{x}_{\mathrm{i}}, \mathrm{i}=1 \ldots \mathrm{n}-\right.$ elements of Electronic Engine Management Systems affecting the Performance of an Automobile Engine; $q_{c m}^{f}$ - Actual Static Performance of the Fuel System; $q_{c m}^{n}$ - Software Value of the Static Performance of the Fuel System)

Operational experience, as well as conducted studies showed that the different technical state of mechatronic system elements affects the output parameters of engines that have a significant variation. This is due to the fact that the fuel supply by the injector, calculated by the ECU program, is determined by the value of the static injector output $q_{c m}^{n}$ set in the ECU software. The actual fuel supply differs from the calculated one due to the change of the actual pressure in a fuel system and by the change in the technical state of the mechatronic system elements. Thus, the actual value of the fuel system performance $q_{\mathrm{cm}}^{f}$ differs from the program one, i.e. $q_{c m}^{f} \neq q_{c m}^{n}$. The discrepancy between these values leads to the disruption in the composition of the working mixture, whose complex quality factor is the excess air factor $\alpha$.

The provisions of image recognition theory, namely diagnostics by distance in the space of characteristics are used for the localization of faults.

The point $\mathrm{O}$ of function graph intersection of the graphs of the functions received on the serviceable engine is taken as the first reference state. This condition can be represented in the form of the reference region $\mathrm{D}_{\mathrm{st} 0}$ :

$$
D_{s t 0}=\left\{\begin{array}{l}
f_{1}\left(q_{c m}^{n}\right)=f_{2}\left(q_{c m}^{n}\right) \\
\alpha=1 \pm 0,05 ; \\
C O=O_{2}=Y^{x} \% .
\end{array}\right.
$$

Then the region in which the point Oi falls during the diagnosis can be represented as follows:

$$
D_{i}=\left\{\begin{array}{l}
f_{1}\left(q_{c n}^{g}\right)=f_{2}\left(q_{c n}^{g}\right), \\
a_{i}=\sqrt{\alpha^{2}+C O^{2}} ; D_{i} \in \bigcup D_{s t i}, \\
\gamma_{i}=\operatorname{arctg}\left(\frac{C O_{i}}{\alpha_{i}}\right) .
\end{array}\right.
$$

(8)

where $\bigcup D_{s t i}$ is a set of reference areas corresponding to different states of the diagnostic object.

The assignment of the diagnostic region $D_{i}$ to any of the reference areas is based on the use of a distance measure to the reference region $D_{\text {sti }}$ (Fig. 2). 




Fig. 2. Scheme for Determining the Distance $r$ to the Reference Area $\mathrm{O}_{\text {sti }}$

The recognition of an image is reduced to the following. Let's assume that the feature space uses the diagnostic measure of the distance $r$ and an object $x$ is presented for diagnosis. In order to assign an object $\mathrm{x}$ to one of $n$ diagnoses, the distances $r$ to the reference points $\mathrm{O}_{\text {st1 } 1}, \mathrm{O}_{\text {st2 }}, \ldots, \mathrm{O}_{\text {stn }}$ are determined. The object $\mathrm{x}$ is referred to the diagnosis $\mathrm{D}_{\text {sti }}$, if the measure of the distance between the points $\mathrm{x}, \mathrm{r}_{\mathrm{i}}$ is minimal:

$$
\text { если } \mathrm{r}_{\mathrm{i}}=\sqrt{\Delta \alpha^{2}+\Delta C O^{2}}=\min \text {, то } \mathrm{x} \in \mathrm{D}_{\mathrm{sti}}, \text { (9) }
$$

\section{Results}

The implementation of the developed theoretical provisions was carried out during the pilot study of electronic engine control systems for LADA vehicles using the diagnostic algorithm (Fig. 3).

If composition of the working mixture is broken during the deviation of element technical parameter state from a serviceable one, then the region of $\mathrm{CO}$ and $\mathrm{O}_{2}$ curve intersection will shift by a certain distance from the initial position. Thus, a reference area is formed that corresponds to this particular malfunction or deviation in operation. 

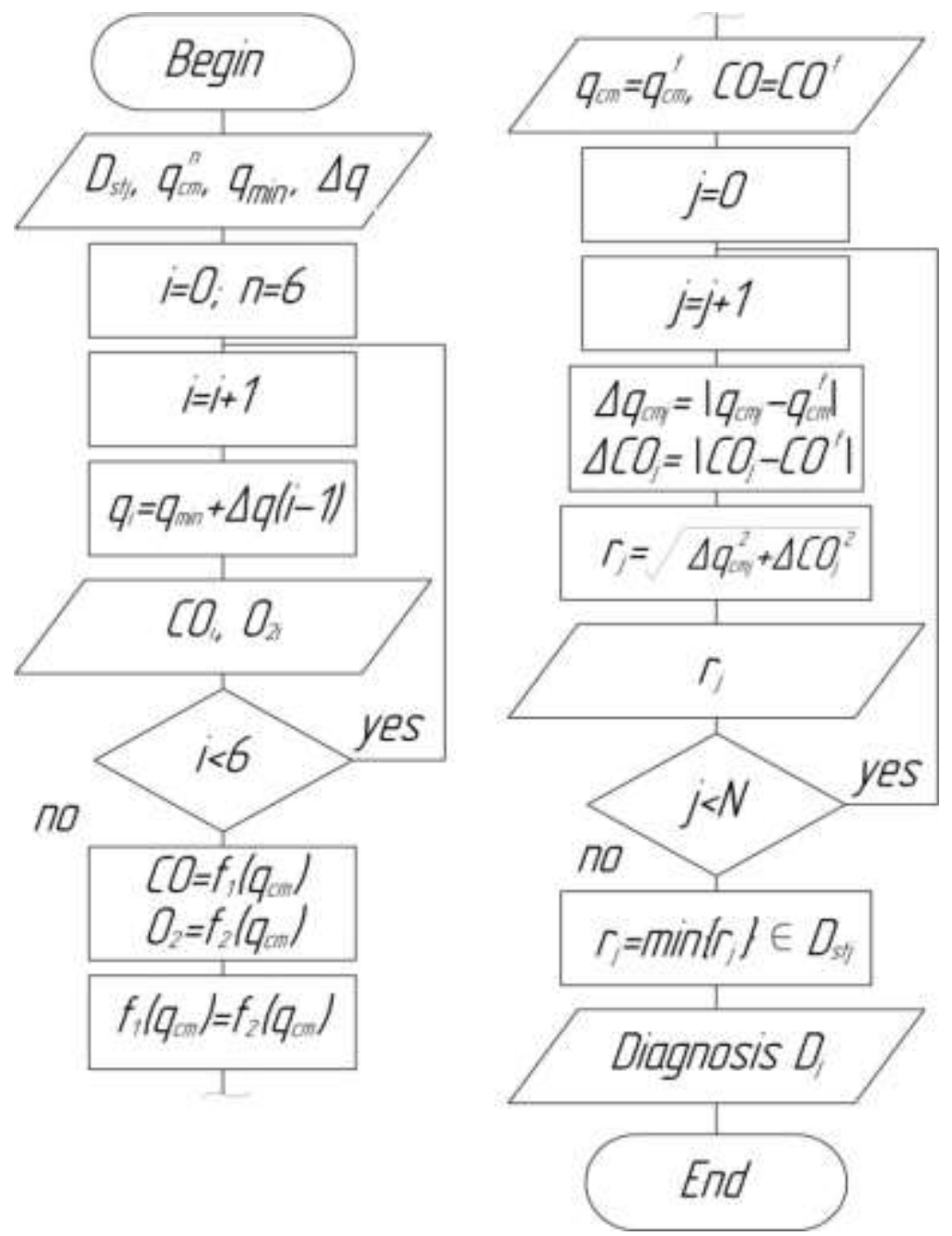

Fig. 3. Algorithm for Diagnosing Automotive Mechatronic Systems

Fig. 4 shows the results of the reference diagnostic area establishment $\mathrm{D}_{\mathrm{i}}$ corresponding to i-th faults.

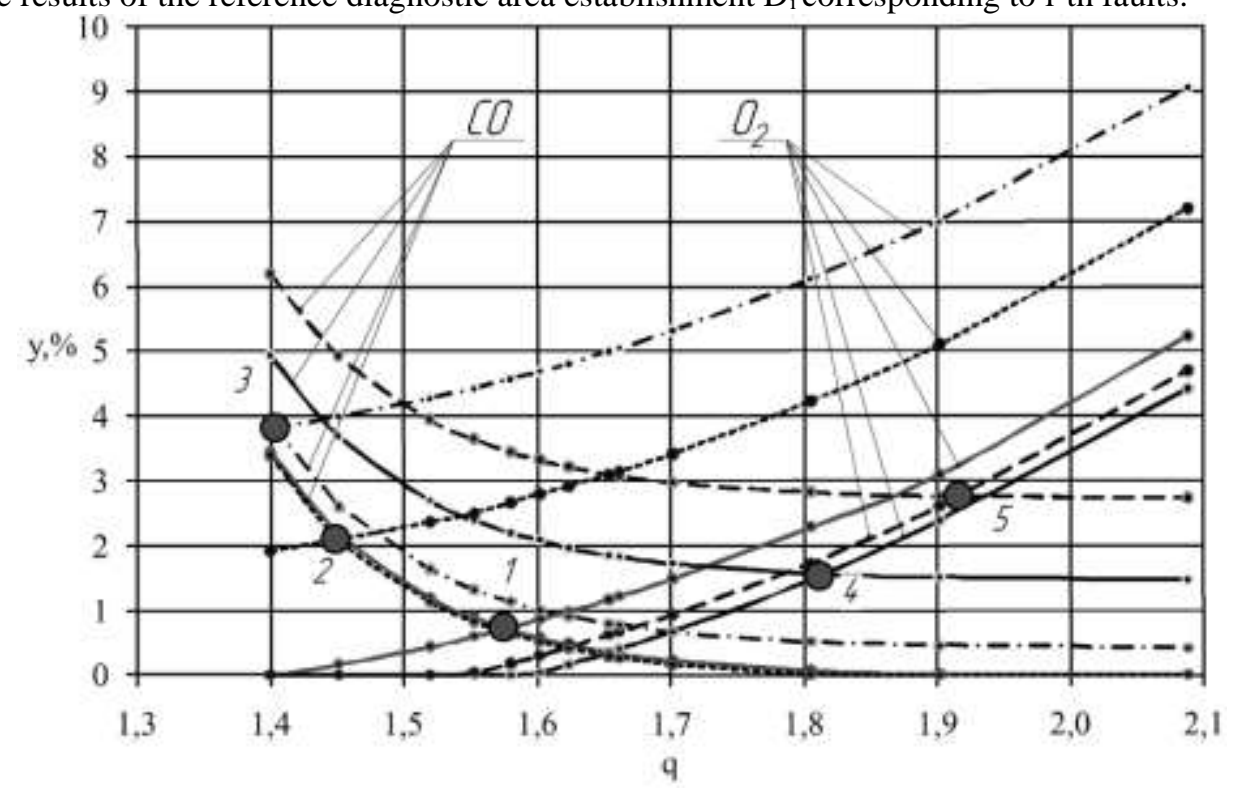

Fig. 4. The Result of the Establishment of Reference Areas $D_{i}$, Corresponding to Faulty States of the Electronic Engine Management System (1 - Working Condition; 2 - Malfunctions of Fuel Equipment; 3 - Ignition System Malfunction; 4 - Deviations in the Operation of the Mass Air Flow Sensor; 5 - Malfunction of the Mass Air Flow Sensor) 
The centers of the reference regions obtained as the result of the pilot study carried out on the reference engine were adopted as a basis to set the dimensions of the reference areas when a part of the experiment is carried out on a representative sample of vehicles in service.

The result of the experimental study is the parameters of the reference regions: $\mathrm{L}_{\mathrm{i}}$ - the distances from the center of the zero region to the center of the i-th diagnostic area, $\gamma_{i}$ is the angle of vector inclination drawn from the center of the zero region relative to the abscissa axis; $r_{i}$ is the radius of the circle with the center in the i-th reference region, which characterizes the scattering of diagnostic features in space.

Fig. 5 shows the results of diagnostic area parameter setting.

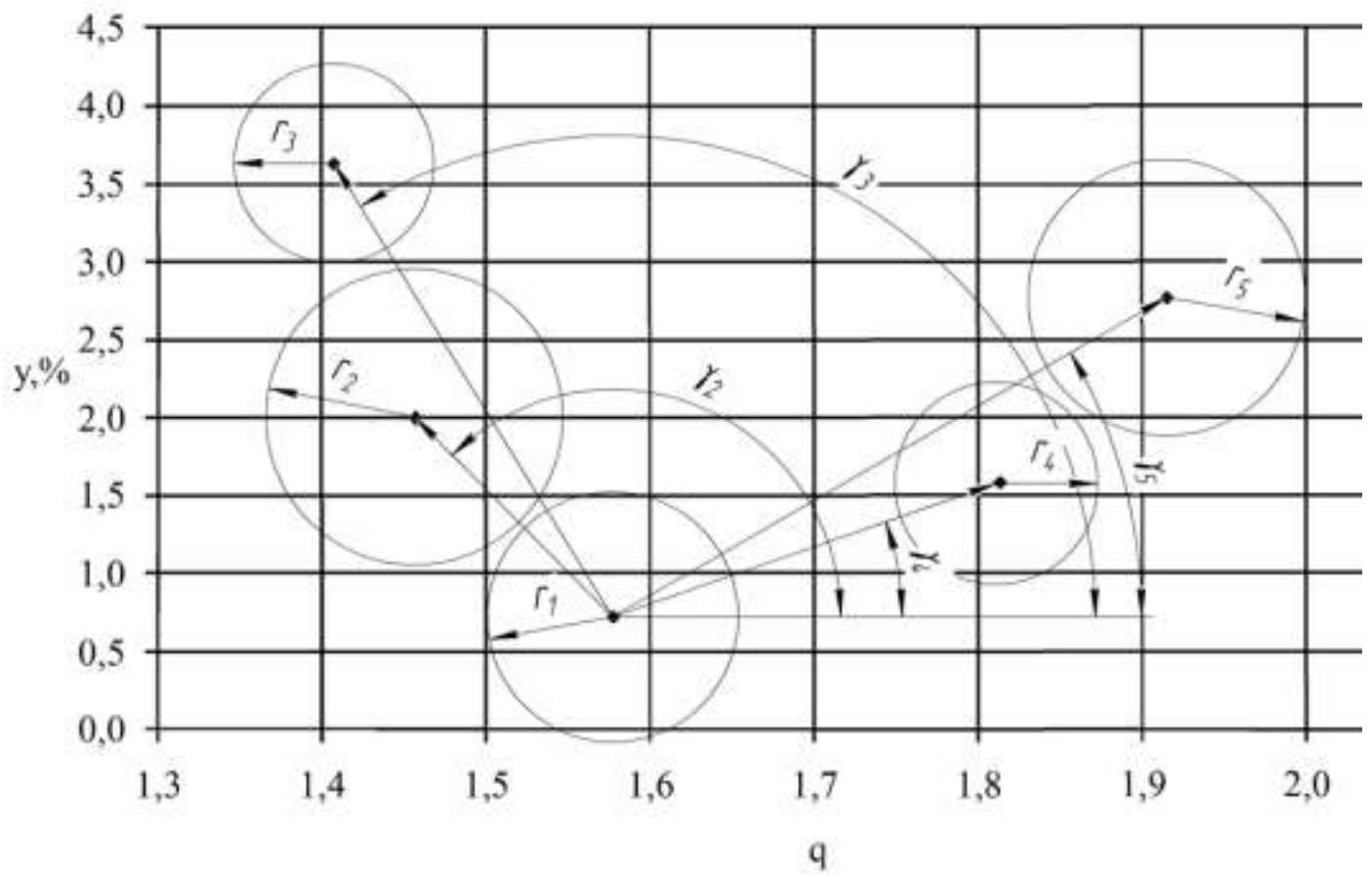

Fig. 5. The Results of Setting the Parameters of Diagnostic Areas

In order to reduce the complexity of EECS diagnosis in operation, it is proposed to use the technique based on the parallel transfer of $\mathrm{CO}$ and $\mathrm{O} 2$ curves corresponding to the working state into a new area based on gas analysis results. To do this, we introduce the parameters $\Delta_{C O_{i}}$ и $\Delta_{O_{2 i}}$ in the equations of the expression (8):

$$
\begin{aligned}
& C O_{i}=6,4364 \cdot 10^{5} \cdot e^{-8,67 q_{c m}^{n}}+\Delta_{C O i} \\
& O_{2 i}=6,86 \cdot\left(q_{c m}^{n}\right)^{2}-16,318 \cdot\left(q_{c m}^{n}\right)+9,41+\Delta_{O_{2 i}}
\end{aligned}
$$

Equating the values of $\mathrm{CO}$ and $\mathrm{O}_{2}$, and also taking $\Delta_{C O_{i}}=C O_{\text {изм }}-C O_{0}$, $\Delta_{O_{2 i}}=O_{2_{0}}-O_{2 \text { изм }}$, we determine the value $q_{c m}^{n}$, corresponding to the intersection point of the curves. 


\section{Conclusions}

The use of the developed technique for mechatronic system diagnosing using telematic means allows to identify an operatively faulty subsystem and to establish a specific malfunction according to the developed algorithm based on standard diagnostic procedures.

The developed mathematical model establishes the relationship between the concentration of $\mathrm{CO}$ and $\mathrm{O}_{2}$ in the exhaust gases of automobile engines with the parameters of mechatronic system element technical state, characterized by the change of excess air coefficient, which makes it possible to assess their technical condition objectively and reasonably.

The developed diagnostic technique allows to evaluate the mechatronic system element technical state based on the assignment of diagnostic parameters (combination of $\mathrm{CO}, \mathrm{O}_{2}$ and $\mathrm{q}_{\mathrm{st}}$ ) to the reference diagnostic areas corresponding to specific faults of mechatronic system elements.

\section{Summary}

As a result of the pilot study, the analytical relationship was established between the concentration of $\mathrm{CO}$ and $\mathrm{O}_{2}$ in the exhaust gases with an excess air factor, on the basis of which the parameters of the reference diagnostic areas were established. The correct state corresponds to the region with the center $\mathrm{q}_{\mathrm{st}}=1.6 \pm$ $0.1, \mathrm{mg} / \mathrm{ms}, \mathrm{CO}=0.7 \pm 0.2 \%$; the faults in the fuel system are represented by the values $\mathrm{q}_{\mathrm{st}}=1.45 \pm 0.05$ $\mathrm{mg} / \mathrm{ms}, \mathrm{CO}=2 \pm 1 \%$; the faults of the ignition system correspond to the values $\mathrm{q}_{\mathrm{st}}=1.4 \pm 0.05 \mathrm{mg} / \mathrm{ms}, \mathrm{CO}=$ $4 \pm 1 \%$; the deviations in the work of the mass air flow sensor are represented by the values of $\mathrm{q}_{\mathrm{st}}=1.8 \pm 0.1$ $\mathrm{mg} / \mathrm{ms}, \mathrm{CO}=1.5 \pm 0.5 \%$; the malfunctions of the mass air flow sensor are represented by the values of $\mathrm{q}_{\mathrm{st}}=$ $1.95 \pm 0.06 \mathrm{mg} / \mathrm{ms}, \mathrm{CO}=3 \pm 1 \%$.

The diagnostic technique developed as the result of the theoretical and experimental studies made it possible to build a general technology to diagnose engines, which reduces labor intensity by $10 \%$ and improves the accuracy and the reliability of the diagnosis.

\section{Acknowledgements}

The work is performed according to the Russian Government Program of Competitive Growth of Kazan Federal University.

\section{References}

1. Vorobyov S., Chernyaev I., Nazarkin V., Filippov K. Model of Operation of Motor Vehicles Based on Monitoring of Their Performance Characteristic//12th International Conference "Organization and Traffic Safety Management in large cities", SPbOTSIC-2016, 28-30 September 2016, St. Petersburg, Russia
2. Pribyl P., Svitek M. Telematics in transport. Edited by prof. Silyanov V.V. Moscow: MADI (STU), 2003. $540 \mathrm{p}$.

3. Folkson R. Alternative Fuels and Advanced Vehicle Technologies for Improved Environmental Performanceб 1st Edition Towards Zero Carbon Transportation Editors, Woodhead Publishing, 2014. 784 pp.

4. Martyr A. J. Engine Testing, 4th Edition, The Design, Building, Modification and Use of Powertrain Test Facilities, Butterworth-Heinemann, 2012 - 600 pp.

5. Toru S., Takahiko K., Yasuo A. Calibration of fundamental diagram using trajectories of probe vehicles: Basic formulation and heuristic algorithm //Transportation Research Procedia, Volume 21, 2017, pp. 6-17.

6. Sideris M. Methods for Monitoring and Diagnosing the Efficiency of Catalytic Converters, Volume 115, 1st Edition, Elsevier Science, 1998. - 446 pp.

7. Crolla, D. Automotive Engineering, 1st Edition, Powertrain, Chassis System and Vehicle Body, Butterworth-Heinemann, 2009. - 834 pp.

8. Goncharov A.A. The improvement of the methodology to obtain general system characteristics (monitoring) / A.A. Goncharov, P.A. Goncharov // Progressive technologies in transport systems: Collection of papers of the VI Russian Scientific and Technical Conference. - 2003. - pp. 63 - 64.

9. Bondarenko E.V. The procedure for electronic system of engine management diagnosing / E.V. Bondarenko, A.A. Goncharov, P.A. Goncharov, A.N. Melnikov // Monthly scientific and production magazine "Autotransport enterprise". 2011. № 9. pp. 43-45 ISSN 2076-3050. 